\title{
Meiotic behavior of Brachiaria decumbens
} hybrids

\author{
V.F. Souza ${ }^{1}$, M.S. Pagliarini2 ${ }^{2}$, C.B. Valle ${ }^{3}$, N.C.P. Bione ${ }^{4}$, M.U. Menon ${ }^{5}$ and \\ A.B. Mendes-Bonato ${ }^{2}$ \\ ${ }^{1}$ Departamento de Agronomia, Universidade Estadual de Maringá, Maringá, \\ PR, Brasil \\ ${ }^{2}$ Departamento de Biologia Celular e Genética, \\ Universidade Estadual de Maringá, Maringá, PR, Brasil \\ ${ }^{3}$ Embrapa Gado de Corte, Campo Grande, MS, Brasil \\ ${ }^{4}$ Departamento de Engenharia Ambiental, \\ Universidade Estadual do Centro-Oeste, Irati, PR, Brasil \\ ${ }^{5}$ Setor de Ciências Agrárias e Ambientais, \\ Universidade Estadual do Centro-Oeste, Irati, PR, Brasil \\ $\dagger$ In memoriam \\ Corresponding author: V.F. Souza \\ E-mail: vivifdesouza@hotmail.com
}

Genet. Mol. Res. 14 (4): 12855-12865 (2015)

Received February 17, 2015

Accepted June 12, 2015

Published October 21, 2015

DOI http://dx.doi.org/10.4238/2015.October.21.5

\begin{abstract}
Brachiaria decumbens is a forage grass of inestimable value for livestock in Brazil due to its production of good quality forage even when planted on acid and poor soils, although it is susceptible to pasture spittlebugs. Only one cultivar, cv. Basilisk, has been used as the pollen donor in crosses with Brachiaria ruziziensis since 1988 at Embrapa Gado de Corte Research Center. Breeding within the species only became possible from 2009 when sexual accessions were successfully tetraploidized using colchicine. Three sexual genotypes were obtained and hybridization within $B$. decumbens
\end{abstract}


was finally achieved. Here, we evaluated microspore tetrads using conventional cytology and found meiotic indexes above $78 \%$ for all three female genitors (cD24-2, cD24-27, cD24-45), but a low meiotic index $(<22 \%)$ in the natural apomictic genitor D62 (cv. Basilisk) and in 49 hybrids. Analysis of the relationship between abnormal tetrad frequency and non-viable pollen grains yielded a highly significant Pearson correlation coefficient. The $t$-test proved significant for the progeny of cD24-45 x D62, with lower abnormalities and pollen sterility when compared to the other two progenies resulting from cD24-2 and cD24-27 crossed to D62, but these two did not differ. Apomictic hybrids such as S036 and X030 with low pollen sterility have the potential for use in cultivar development, whereas the sexual hybrids T012, X072, and X078 might be of use as female genitors in polycross blocks if they display good agronomic traits.

Keywords: Apomictic hybrids; Forage grass; Intraspecific breeding; Meiotic abnormalities; Meiotic index; Sexual hybrids

\section{INTRODUCTION}

Brachiaria is a grass genus containing about 100 species, mostly from Africa. Some species have great importance as forage (Valle et al., 2009) and are used throughout the tropical and subtropical regions of the world. One vigorous ecotype of Brachiaria decumbens from Uganda was registered in Australia, in 1930, as cultivar Basilisk (Mackay, 1982). Introduced into Brazil in 1952, B. decumbens $\mathrm{cv}$. Basilisk became the most used grass for pastures as a result of by means of governmental incentives during the 1960s (Pizarro et al., 1996). Despite its susceptibility to pasture spittlebugs and a possible association with photosensitization in calves, sheep, and goats (Fagliari et al., 2003), this cultivar has valuable characteristics for use in livestock feeding and became the largest pasture monoculture in the 1990s (Usberti, 1990). B. decumbens is very tolerant of high aluminum concentrations and low nutrient content in the soil, is easy to establish by seeding, and produces good quality forage throughout the year (Karia et al., 2006).

Due to its extensive root system, it can also be used to regenerate degraded soils in construction areas of hydroelectric power plants, mining regions, and roadsides. Yes, the greatest concentration of the root system and greater addition of organic matter will allow the improvement of macro and microporosity in soil structure (Alves et al., 2012). It can also improves soils in crop-livestock systems by producing mulch for no-till seeding of soybean crops (Macedo, 2009).

Brachiaria seed production represents an economically significant commercial product in Brazil, the largest producer and exporter of this commodity to the tropical world, since most beef and dairy production is based on pastures (Jank et al., 2011). Due to the importance of Brachiaria for pastures in Brazil, research to develop cultivars with higher production and better animal performance has been carried out at Embrapa Gado de Corte Research Center for over two decades (Valle et al., 2008). Breeding of $B$. 
decumbens commenced relatively recently (2009) and is aimed mainly at incorporating resistance to pasture spittlebugs and improving agronomic and nutritive value attributes (Karia et al., 2006).

Intra- and interspecific hybrids with favorable genetic combinations may be obtained through meticulous selection of genitors. This selection means favorable genetic combinations, for it is necessary to know previously reproductive aspects, physiological, and agronomic characteristics, as well as chromosome behavior and ploidy levels of compatible species and genotypes. The choice of sexual and apomictic genitors for each cross is important for the success of the program. Hybridization between genotypes of the same species may minimize possible incompatibility problems, and may favor fertility and recombination of favorable alleles in comparison to interspecific hybridization (Valle et al., 2008).

Hybridization within and between species in the genus Brachiaria is not an easy task since the majority of accessions are polyploid and, in this genus, polyploidy is associated with apomixis (Valle and Pagliarini, 2009). Crosses are only successful between accessions of same ploidy level with a sexual parent as the pollen receptor and an apomictic parent as the pollen donor, normally an elite cultivar or pre-selected genotype. Sexual reproduction in polyploids may be achieved by artificial polyploidization of sexual diploid accessions. Diploid, tetraploid and pentaploid accessions of $B$. decumbens are held in the germplasm bank at Embrapa Gado de Corte Research Center (Ricci et al., 2011). Polyploidization was induced using colchicine treatment of sexual diploid accessions in experiments carried out between 2004 and 2007 (Valle et al., 2008; Simioni and Valle, 2009, 2011). Three tetraploid plants were obtained and named cD24-2, cD24-27, and cD24-45. These were later crossed to the apomictic tetraploid accession D62 (Basilisk) as the male genitor (Valle et al., 2008; Simioni and Valle, 2011). In 2009, several hundred hybrids were produced and, after agronomic evaluation, 49 were considered as promising and selected for cytogenetic evaluation. The present study reports on the chromosomal behavior of these hybrids and on pollen viability in the parental material. An index of the frequency of meiotic abnormalities in tetrads was established, and the correlation between meiotic products and the frequency of non-viable pollen was determined.

\section{MATERIAL AND METHODS}

Three sexual plants of $B$. decumbens (cD24-2, cD24-27, cD24-45), artificially induced to become tetraploid $(2 \mathrm{n}=4 \mathrm{x}=36)$, were crossed to cultivar Basilisk (apomictic and natural tetraploid). The hybrids produced were planted in an experimental field at Embrapa Gado de Corte Research Center in Campo Grande, MS, latitude 20 $25^{\prime} 03^{\prime \prime} \mathrm{S}$ and longitude 54 $42^{\prime} 20^{\prime \prime} \mathrm{W}$ in a 'Latossolo Roxo Álico-type' soil. A preliminary evaluation identified 49 promising hybrids based on vigor, leaf density and flowering potential. The crosses and their progenies and modes of reproduction are presented in Table 1.

For chromosomal analysis and pollen viability determination, inflorescences within the flag leaf were collected and fixed in ethyl alcohol, chloroform and propionic acid $(6: 3: 2 \mathrm{v} / \mathrm{v} / \mathrm{v})$ for 24 hours. The tissues were washed in $70 \%$ alcohol and transferred to fresh alcohol and refrigerated until used for analysis. The cytogenetic analysis was carried out at the Plant Cytogenetics Laboratory at the Universidade Estadual de Maringá. Microsporocytes were prepared using the traditional squashing technique and stained with 
$1 \%$ propionic carmine. A minimum of 100 cells at the tetrad stage from different points in the inflorescences were used for each analysis. To evaluate the final product of meiosis, a meiotic index (MI) was calculated using the equation proposed by Love (1949) in which the frequency of normal cells is considered: $\mathrm{MI}=$ number of normal cells / total number of tetrads x 100 .

To analyze pollen viability, anthers were extracted from the inflorescences and transverse sections were cut to obtain grains from all three anthers of the same flower. The pollen grains were stained with $1 \%$ propionic carmine. Ten flowers from 10 different inflorescences were analyzed for each genotype. One hundred randomly selected pollen grains were analyzed per slide. Pollen was classified as non-viable if the size was visibly altered, or if it showed weak staining, or if it had reduced or absent protoplasm. Viable pollen had an intact exine, was strongly stained, and had homogeneously distributed protoplasm.

Through the frequency of meiotic abnormalities in tetrads, the end product of meiosis, it has been estimated the correlation between the product and the frequency of meiotic polens unviable for the three progenies. This estimate was aimed at checking whether there was significant difference between crosses and if there is high correlation between the abnormalities and viability of pollen.

We used a Pearson correlation (r) analysis to look for an association between the rate of normal meiosis and the frequency of viable gametes. The interpretation of the magnitude of $r$ followed that suggested by Cohen (1988): values between 0.10 and 0.29 were considered low (weak association); values between 0.30 and 0.49 were intermediate (moderate association); and values between 0.50 and 1 were high (strong association). Perfect correlation (-1 or 1) means that the value of one variable determines exactly the value of the associated variable. At the other extreme, zero correlation means there is no association between the two variables (Figueiredo Filho and Silva Júnior, 2009).

To compare pollen viability among the progeny of the three crosses, the Student $t$-test was used, with a $95 \%(\mathrm{P}<0.05)$ confidence level. The statistical analysis for the $t$-test used the averages of frequencies of non-viable pollen between two crosses: (cD24-2 x D62 and cD24-27 x D62); (cD24-2 x D62 and cD24-45 x D62); (cD24-27 x D62 and cD24-45 x D62), presuming that the progeny from the cross between the accesses cD24-45 x D62 differs significantly from the other two progenies from hybrids of $B$. decumbens.

Images of pollen grains with the most representative abnormalities were captured using and optical Olympus microscope CX31, camera SC30 by the AnalySIS getIT program.

\section{RESULTS AND DISCUSSION}

Analysis of pollen viability in the sexual tetraploidized genitors (cD24-2; cD2427 ; cD24-45), the apomictic genitor (D62), and the hybrids from the three crosses revealed a high frequency of abnormalities and sterility (Table 1). In all plants examined, pollen grains of different sizes and different staining intensities were seen. Pollen grains with an intact exine and containing well-stained protoplasm with a homogeneous distribution were considered viable. Those that were visibly abnormal in size, showed weak staining, and had reduced or missing protoplasm were classified as non-viable pollen grains (Figure 1a). 
Table 1. Mode of reproduction, percentage of abnormal tetrads, meiotic index and percentage in ascending order of pollen sterility of parents and Brachiaria decumbens hybrids resulting from crosses between tetraploidized accessions (cD24-2; cD24-27; cD24-45) and cv. Basilisk (D62), a natural tetraploid.

\begin{tabular}{|c|c|c|c|c|}
\hline Genotype & Mode of reproduction & $\%$ abnormal tetrads & Meiotic index & $\%$ pollen sterility \\
\hline \multicolumn{5}{|c|}{ cD24-2 x D62 } \\
\hline cD24-2 & SEX & 21.60 & 78.40 & 43.91 \\
\hline D62 & APO & 78.58 & 21.42 & 87.39 \\
\hline B009 & $\mathrm{APO}$ & 98.46 & 1.54 & 80.71 \\
\hline A026 & $\mathrm{APO}$ & 86.46 & 13.54 & 86.87 \\
\hline A003 & APO & 89.94 & 10.06 & 90.37 \\
\hline A015 & APO & 94.06 & 5.94 & 92.20 \\
\hline A038 & APO & 86.40 & 13.60 & 93.33 \\
\hline B003 & SEX & 96.40 & 3.60 & 94.94 \\
\hline $\mathrm{C} 001$ & SEX & 98.70 & 1.30 & 91.41 \\
\hline B021 & SEX & 91.90 & 8.10 & 92.22 \\
\hline B006 & SEX & 100.00 & 0.00 & 98.72 \\
\hline \multicolumn{5}{|c|}{ cD24-27 x D62 } \\
\hline $\mathrm{cD} 24-27$ & SEX & 21.35 & 78.65 & 64.07 \\
\hline D62 & $\mathrm{APO}$ & 78.58 & 21.42 & 87.39 \\
\hline S036 & APO & 92.34 & 7.66 & 73.62 \\
\hline R041 & APO & 93.00 & 7.00 & 81.90 \\
\hline T044 & APO & 100.00 & 0.00 & 87.15 \\
\hline S028 & APO & 93.90 & 6.10 & 89.71 \\
\hline R107 & APO & 92.19 & 7.81 & 89.93 \\
\hline R025 & $\mathrm{APO}$ & 93.32 & 6.68 & 91.00 \\
\hline $\mathrm{R} 101$ & APO & 98.28 & 1.72 & 92.45 \\
\hline S031 & APO & 100.00 & 0.00 & 92.52 \\
\hline $\mathrm{R} 120$ & APO & 100.00 & 0.00 & 93.33 \\
\hline R044 & APO & 100.00 & 0.00 & 93.72 \\
\hline R110 & APO & 100.00 & 0.00 & 94.32 \\
\hline R144 & APO & 98.66 & 1.34 & 94.91 \\
\hline R054 & APO & 100.00 & 0.00 & 98.12 \\
\hline T068 & SEX & 96.86 & 3.14 & 80.43 \\
\hline Т009 & SEX & 100.00 & 0.00 & 84.37 \\
\hline R124 & SEX & 100.00 & 0.00 & 85.74 \\
\hline S018 & SEX & 90.38 & 9.62 & 88.48 \\
\hline T054 & SEX & 98.69 & 1.31 & 89.29 \\
\hline T045 & SEX & 100.00 & 0.00 & 89.65 \\
\hline T026 & SEX & 100.00 & 0.00 & 91.67 \\
\hline T066 & SEX & 100.00 & 0.00 & 91.69 \\
\hline T086 & SEX & 87.33 & 12.67 & 93.42 \\
\hline R030 & SEX & 98.66 & 1.34 & 93.48 \\
\hline T005 & SEX & 100.00 & 0.00 & 93.82 \\
\hline R078 & SEX & 98.91 & 1.09 & 94.57 \\
\hline R068 & SEX & 96.83 & 3.17 & 94.63 \\
\hline T007 & SEX & 98.29 & 1.71 & 94.95 \\
\hline T035 & SEX & 98.10 & 1.90 & 95.64 \\
\hline R082 & SEX & 92.85 & 7.15 & 96.11 \\
\hline R014 & SEX & 95.87 & 4.13 & 96.32 \\
\hline T012 & SEX & 87.14 & 12.86 & 73.84 \\
\hline R087 & SEX & 93.55 & 6.45 & 89.91 \\
\hline \multicolumn{5}{|c|}{ cD24-45 x D62 } \\
\hline cD24-45 & SEX & 20.53 & 79.47 & 47.02 \\
\hline D62 & APO & 78.58 & 21.42 & 87.39 \\
\hline $\mathrm{X} 030$ & APO & 88.32 & 11.68 & 73.33 \\
\hline X061 & APO & 100.00 & 0.00 & 86.77 \\
\hline X099 & APO & 97.26 & 2.74 & 90.70 \\
\hline $\mathrm{X} 078$ & SEX & 91.28 & 8.72 & 66.45 \\
\hline X072 & SEX & 85.31 & 14.69 & 70.80 \\
\hline X048 & SEX & 97.76 & 2.24 & 81.24 \\
\hline X006 & SEX & 93.57 & 6.43 & 88.47 \\
\hline X002 & SEX & 88.56 & 11.44 & 89.20 \\
\hline
\end{tabular}




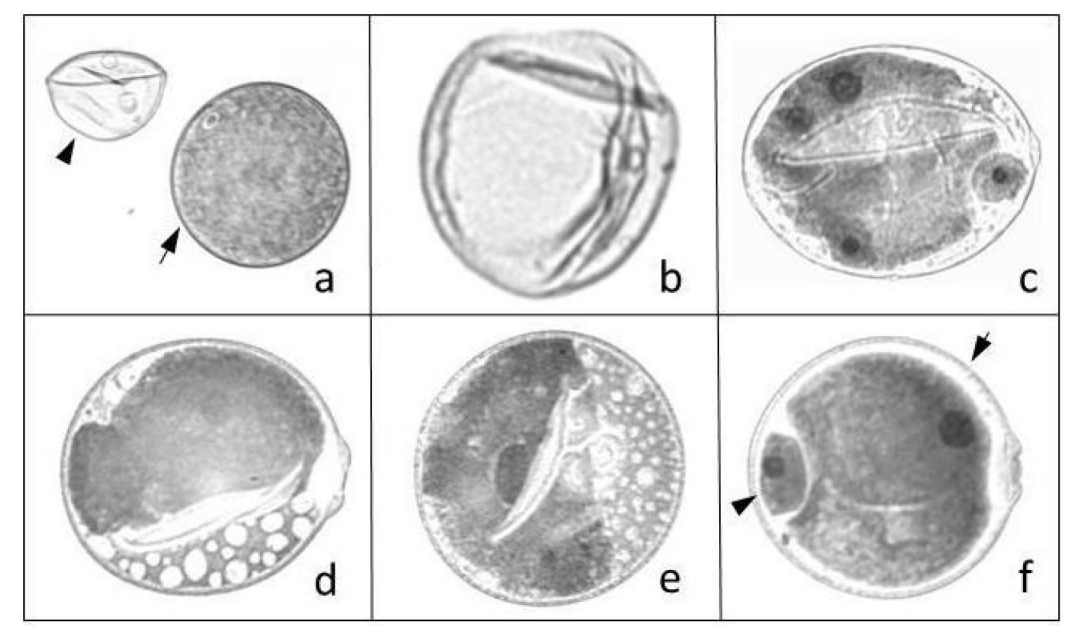

Figure 1. Different aspects of the pollen grains of Brachiaria decumbens. a. Viable pollen grains (arrow) and sterile (arrowhead). b. Empty pollen grain. c. Pollen grain with cytoplasm degeneration. d-e. Pollen grains with numerous vacuoles in the cytoplasm. f. Normal pollen grain with vegetative cell (arrow) and generative cell (arrowhead).

Abnormal chromosome behavior at meiosis may result in a final product with an abnormal complement of chromosomes. Microspores of heterogeneous sizes may indicate variable contents of genetic material, and may generate pollen grains of different sizes. This characteristic has been reported in interspecific hybrids of the genus Brachiaria, where the sizes of pollen grains varied with the number of nuclei and/or micronuclei in each cell (Mendes-Bonato et al., 2001; Fuzinatto et al., 2007; Felismino et al., 2008, 2010).

Pollen fertility is ultimately controlled by the genetic factors that regulate meiosis; incorrect regulation may result in the production of viable or non-viable final products and reduce gametic fertility (Pagliarini, 2000). In this study, these effects were observed in the genitors and were especially prominent in $B$. decumbens hybrids that had completely empty pollen grains (Figure $1 \mathrm{~b}$ ) as a consequence of the high frequency of abnormal tetrads (Table 1).

In Brachiaria, the various meiotic abnormalities observed in cytogenetic analyses compromise normal chromosome behavior and lead to the formation of infertile gametes (Risso-Pascotto et al., 2005; Mendes-Bonato et al., 2002, 2004, 2007; Fuzinatto et al., 2007; Felismino et al., 2008, 2010, Ricci et al., 2010, 2011; Souza-Kaneshima et al., 2010; Pagliarini et al., 2012a,b).

Meiotic stability can be quantified using the MI, which provides an estimation of gametic viability from the frequency of normal tetrads (Love, 1949). Pollen mother cells with four microspores in the tetrads are considered normal; those with micronuclei, an abnormal number of microspores, such as polyads, or containing microcytes are considered abnormal. The MIs of tetraploidized plants of $B$. decumbens were relatively high: $78.40 \%$ (cD24-2); $78.65 \%$ (cD24-27), and 79.47\% (cD24-45) (Table 1).

Love (1949) proposed that values below $90 \%$ may be considered balanced, so these genitors can be considered meiotically stable with values close to the ideal. However, the MI of the male parent (D62) was found to be even lower at $21.42 \%$. The progeny resulting from the three intraspecific crosses in $B$. decumbens showed extremely low MIs, from zero to $14.69 \%$ (Table 1), and were, therefore, highly unbalanced. 
Pollen analysis of the parental plants and hybrid progenies showed a high frequency of sterility. The low MI observed among hybrids was the result of the high frequencies of sterile pollen grains, which ranged from 66.45 to $98.72 \%$ (Table 1 ).

The assessment of pollen viability is a criterion of great importance for plant breeding as it provides crucial information for species conservation and planning of the breeding program. The use of dyes to screen pollen viability offers a fast method that is widely exploited (Galletta, 1983). However, simply because a pollen grain shows a viable staining pattern does not ensure that it can actually function to fertilize an egg cell and polar nuclei (Shivanna, 2003).

In the hybrid B003 (cD24-2 x D62), the large frequency of empty pollen grains resulted in an estimate of $94.94 \%$ sterility (Table 1 ). Only $2.62 \%$ of the non-viable pollen (25 in 956 pollen grains examined) had any reduction in the intensity of cytoplasmic staining (Figure 1c) or had large numbers of vacuoles in the cytoplasm (Figure 1d-e).

Inflorescences evaluated for pollen viability in the hybrid B009 had several racemes with flowers containing anthers full of empty pollen grains; these pollen grains were completely transparent and gave an estimate of $80.71 \%$ pollen sterility (Table 1). However, in other racemes, the flowers had normal anthers that contained fully developed pollen grains, which stained normally, and had normal vegetative and generative cells (Figure 1f). In 1037 grains analyzed, 200 were viable; of these viable grains, only eight had normal vegetative and generative cells, giving an estimate of $4 \%$ viable pollen.

Meiotic abnormalities compromise pollen fertility and thereby affect the breeding performance of accessions and hybrids, making them poor choices for use as cultivars (MendesBonato et al., 2004). Abnormalities that affect pollen fertility have been identified in accessions of different species in the Brachiaria germplasm collection at the Embrapa Beef Cattle Research Center (Mendes-Bonato et al., 2002, 2007; Risso-Pascotto et al., 2002) and in their interspecific hybrids (Mendes-Bonato et al., 2004, 2007; Risso-Pascotto et al., 2004; Fuzinatto et al., 2007; Felismino et al., 2008; Pagliarini et al., 2012b). Irregular differentiation of vegetative and generative cells has been reported in $B$. decumbens cv. Basilisk (Junqueira Filho et al., 2003 ) and in one accession of $B$. jubata (Risso-Pascotto et al., 2005).

Given that pollen grains are formed from microspores at the end of meiosis, it is expected that the frequency of abnormalities, especially those persisting until the formation of tetrads, will be correlated with pollen sterility. Here, we obtained an estimate of $r=0.80$, a high Pearson correlation coefficient, for the female parents (cD24-2; cD24-27; cD24-45), the male parent (D62), and the hybrids of $B$. decumbens. The Pearson coefficient is a measure of the linear association between variables and assumes that an increase in one variable will automatically cause an increase in a related variable (Figueiredo Filho and Silva Júnior, 2009).

The female parents had much lower frequencies of abnormal tetrads and pollen sterility compared to the apomictic parent and the hybrids. The cultivar Basilisk had a high frequency of abnormal tetrads and pollen sterility but since only the polar nuclei need to be fertilized for good endosperm formation in this apomictic cultivar, even a small number of viable pollen grains might be sufficient for good seed fill, as is normally observed in seed plots of this cultivar in Brazil. Previous investigation into this cultivar detected high levels of meiotic irregularities resulting in $94.30 \%$ abnormal tetrads (Ricci et al., 2011); in this study, we found $78.58 \%$ (Table 1 ).

Theoretically, it is possible to measure the degree and direction of the relationship between two quantitative variables (Moore, 2007). Two variables are deemed positively related if an increase in one reflects an increase in the other, showing similar distribution of values 
(Figueiredo Filho and Silva Júnior, 2009). In practice, correlation analyses help to determine if abnormalities observed in cell division will actually affect seed fill in the field. For apomictic genotypes, these abnormalities may not be as critical as in sexual varieties, which depend on the quantity of pollen with good fertility for the formation of both the embryo and endosperm.

A relatively weak Pearson correlation $(r=0.12)$ was found for the cD24-2 x D62 hybrids, while a moderate correlation $(\mathrm{r}=0.41)$ was found for the $\mathrm{cD} 24-27 \times \mathrm{D} 62$ hybrids. Only the cD24-45 x D62 cross gave a strong correlation $(r=0.54)$. These results indicate that the levels of abnormalities are not always related to infertility, and that this association is genotype-dependent.

The hybrids A003, A026, B021 (cD24-2 x D62), and R014 (cD24-27 x D62) showed an almost perfect correlation, with only a small difference in the rates of abnormal tetrads and infertile pollen $(<0.5 \%$; Table 1$)$. A perfect correlation would mean the value of one variable determines the value of the other, but such extreme values of 0 or 1 are very rarely found (Figueiredo Filho and Silva Júnior, 2009).

The hybrids B009 (cD24-2 x D62), S036 (cD24-27 x D62) and X078 (cD24-45 x D62) had very curious behavior, since they displayed lower frequencies of non-viable pollen despite high frequencies of abnormal tetrads. The hybrids B006, R044, R054, R110, R120, R124, S031, T005, T009, T026, T044, T045, T066, and X061 also showed a peculiar behavior since $100 \%$ of the tetrads were affected but pollen sterility was lower than expected (Table 1). This may indicate that the abnormalities were not sufficiently severe to produce infertility. Similar results were reported for $B$. decumbens accessions which had apparently normal pollen but in which $100 \%$ of the tetrads had micronuclei or were fragmented into polyads (Ricci et al., 2010).

The female parents, cD24-2, cD24-27, and cD24-45 had rates of non-viable pollen ranging from 43.91 to $64.07 \%$ (Table 1). An earlier evaluation by Simioni and Valle (2011) of plants with the same genotypes also pointed to fertility rates of 61.36 to $64.86 \%$. The sexual diploid accession D24, from which these female parents originated, had only $4.06 \%$ abnormal tetrads (Ricci et al., 2011). This low rate may be due to the greater need for normal meiosis in sexual accessions to produce viable pollen in order to produce viable seeds. However, polyploidy complicates the meiotic process and may compromise pollen viability (Fuzinatto et al., 2007).

The production of fertile pollen involves a great number of physiological, morphological, and biochemical processes that are under genetic regulation in the flower. Any interruption during the development of the stamens, such as to the differentiation of sporogenic cells, meiosis, the development of the free microspores, mitosis, the differentiation of the microspore into pollen, or anthesis can result in male sterility in the plant (Glover et al., 1998).

Previous studies of the natural tetraploid $B$. decumbens $\mathrm{cv}$. Basilisk reported high frequencies of meiotic abnormalities and pollen sterility (Mendes-Bonato et al., 2001; Junqueira Filho et al., 2003). Since this tetraploid is an apomict that depends solely on the fertilization of the polar nucleus for the formation of the endosperm, while its embryo develops through parthenogenesis of the egg cell, pollen viability is not as critical as in sexual genotypes that need double fertilization. This cultivar is widely used and low seed production has never been an issue for its widespread adoption. Other accessions of $B$. decumbens from the germplasm bank at Embrapa Gado de Corte Research Center show similar behavior (Ricci et al., 2011).

These results suggest that for apomictic hybrids any association between abnormality and pollen sterility has little to no practical implications in the field. For sexual hybrids, however, this association seems to exist. The fact that sexual hybrids depend on the fertilization of both polar nuclei and egg cell an aggravation, thus the importance of a correct choice of sexual 
genitors in the breeding program. The statistical analyses of pollen viability of the progenies from the three intraspecific crosses of $B$. decumbens was performed using a comparison of the means of the frequencies of non-viable pollen between every possible pair of crosses, i.e., (cD24-2 x D62 and cD24-27 x D62), (cD24-2 x D62 and cD24-45 x D62), and (cD24-27 x D62 and cD24-45 x D62), assuming genotypic variances between the progenies. For this comparison, a Student $t$-test was used with a $95 \%$ confidence level (Table 2).

The results of the analyses showed there were no significant differences between the

Table 2. Statistical analysis of pollen viability of the progenies obtained in three intraspecific crosses of Brachiaria decumbens. Comparison of mean frequencies of unviable pollen between crosses, two by two: (cD24-2 x D62 and cD24-27 x D62); (cD24-2 x D62 and cD24-45 x D62); (cD24-27 x D62 and cD24-45 x D-62), assuming variances among the progeny. (Student t-test at a confidence level of 95\%).

\begin{tabular}{|c|c|c|c|c|c|c|}
\hline \multirow[t]{2}{*}{ Parameters } & \multicolumn{6}{|c|}{ Crosses comparison } \\
\hline & cD24-2 x D62 & cD24-27 x D62 & cD24-2 x D62 & cD24-45 x D62 & cD24-27 x D62 & cD24-45 x D62 \\
\hline Mean & 91.19 & 90.32 & 91.19 & 80.86 & 90.32 & 80.86 \\
\hline Variance & 25.80 & 35.90 & 25.8 & 89.25 & 35.90 & 8.25 \\
\hline Observations & 9 & 32 & 9 & 8 & 32 & 8 \\
\hline Hypothesis of mean differences & \multicolumn{2}{|c|}{0} & \multicolumn{2}{|c|}{0} & \multicolumn{2}{|c|}{0} \\
\hline GL & \multicolumn{2}{|c|}{15} & \multirow{2}{*}{\multicolumn{2}{|c|}{$\begin{array}{l}10 \\
2.75\end{array}$}} & \multirow{2}{*}{\multicolumn{2}{|c|}{$\begin{array}{c}8 \\
269\end{array}$}} \\
\hline Stat $\mathrm{t}$ & \multicolumn{2}{|c|}{0.43} & & & & \\
\hline $\mathrm{p}(\mathrm{T} \leq \mathrm{t})$ two-tailed & \multirow{2}{*}{\multicolumn{2}{|c|}{$\begin{array}{l}0.66 \\
2.13\end{array}$}} & \multicolumn{2}{|c|}{0.02} & \multicolumn{2}{|c|}{0.02} \\
\hline t critical two-tailed & & & \multicolumn{2}{|c|}{2.22} & \multicolumn{2}{|c|}{2.30} \\
\hline
\end{tabular}
$\mathrm{P}<0,05$.

progeny of the crosses cD24-2 x D62 and cD24-27 x D62, since the calculated value $(t=0.43)$ was less than the standard $(t=2.13)$ and $p(\mathrm{t})=0.66$. Comparison of the crosses $\mathrm{cD} 24-2 \times \mathrm{D} 62$ and cD24-45 x D62 gave a value of $t=2.75$, which was greater than the standard $(t=2.22)$ and $p(t)=0.02$; thus, there was a significant difference between the progeny of these two crosses. The same is true for the progeny of cD24-27 x D62 and cD24-45 x D62, which gave a value of $t=2.69$, which was greater than the standard $(t=2.30)$ and $p(\mathrm{t})=0.02$ (Table 2). The $t$-test confirmed a significant difference between the progeny of the cross cD24-45 x D62 compared to those of the other two crosses at a $95 \%$ confidence level.

Although the parental plants used for hybridization in this study belonged to the same species and had the same ploidy level, nevertheless, they showed a high frequency of meiotic abnormalities that compromised the fertility of the pollen. Similar behavior has been found in hybrids of $B$. humidicola where the parents had a low frequency of meiotic abnormalities but the hybrid progeny had an unexpectedly high frequency of meiotic abnormalities (Pagliarini et al., 2012b).

Theoretically, intraspecific hybridization should result in fewer meiotic abnormalities compared to interspecific hybridization (Pagliarini et al., 2012b). This was not the case for the progeny analyzed here and is a cause of concern since a regular meiosis is important for ensuring pollen fertility. Apomixis in Brachiaria is pseudogamic (Valle and Savidan, 1996), therefore, fertile pollen is necessary to guarantee endosperm development and good seed fill, and vital for sexual genotypes to ensure embryo and endosperm development.

The hybrid progeny T012 and S036 that resulted from the cross cD24-27 x D62, and the hybrids X030, X072 and X078 that originated from a cross between cD24-45 and D62, showed a satisfactory level of pollen viability, with sterility estimated as $73.84,73.62,73.33$, 70.80 , and $66.45 \%$ respectively. Hybrids S036 and X030 are apomicts and hybrids T012, X072, and X078 are sexual (Table 1). 
With regard to the methods used in breeding of Brachiaria (Karia et al., 2006; Valle et al., 2008), we conclude that the sexual hybrids (T012, X072 and X078) could be used in polycross blocks with other elite sexual hybrids in order to recombine favorable alleles; however, the progeny would need to be checked for meiotic abnormalities. The apomictic hybrids (S036 and X030) could be included in agronomic evaluations as cultivar candidates or could be used as pollen donors in future crosses.

\section{ACKNOWLEDGMENTS}

The authors are thankful for the support of CAPES (Coordenação de Aperfeiçoamento de Pessoal de Nível Superior) and Embrapa Gado de Corte.

\section{REFERENCES}

Alves MC, Nascimento V and Souza ZM (2012). Recuperação em áreas de empréstimo usada para construção de usina hidrelétrica. Rev. Bras. Eng. Agr. Amb. 16: 887-893.

Cohen J (1988). Statistical power analysis for the behavioral sciences. 2nd edn. Hillsdale, New Jersey.

Fagliari JJ, Okuda HT, Passipieri M and Pereira GT (2003). Manifestação clinica, taxas de mortalidade e de prevalência de fotossensibilização em bovinos durante 90 dias de pastejo em Brachiaria decumbens. ARS Vet. 2: 119-125.

Felismino MF, Pagliarini MS and Valle CB (2008). A differential phenotypic expression of a divergent spindle mutation in interspecific Brachiaria hybrids. Cell Biol. Int. 32: 1459-1463.

Felismino MF, Pagliarini MS and Valle CB (2010). Meiotic behavior of interspecific hybrids between artificially tetraploidized sexual Brachiaria ruziziensis and tetraploid apomictic B. brizantha (Poaceae). Sci. Agr. 67: 191-197.

Figueiredo Filho DB and Silva Júnior JA (2009). Desvendando os mistérios do coeficiente de correlação de Pearson (r). Rev. Pol. Hoje 18: 115-146.

Fuzinatto VA, Pagliarini MS and Valle CB (2007). Microsporogenesis in sexual Brachiaria hybrids (Poaceae). Genet. Mol. Res. 6: 1107-1117.

Galletta GJ (1983). Pollen and seed management. In: Methods in fruit breeding (Moore JN and Janick J, eds.). Indiana, Purdue University Press, 23-47.

Glover J, Grelon M, Craig S, Chaudhury A, et al. (1998). Cloning and characterization of $m s 5$ from Arabidopsis: a gene critical in male meiosis. Plant J. 15: 345-356.

Jank L, Valle CB and Resende RMS (2011). Breeding tropical forages. Crop Breed. Appl. Biotechnol. S1: 27-34.

Junqueira Filho RG, Mendes-Bonato AB, Pagliarini MS, Bione NC, et al. (2003). Absence of microspore polarity, symmetric divisions and pollen cell fate in Brachiaria decumbens (Gramineae). Genome 46: 83-88.

Karia CT, Duarte JB, Araújo ACG and Jank L (2006). Desenvolvimento de cultivares do gênero Brachiaria (Trin.) Griseb. no Brasil. 1 ed. Embrapa Cerrados, Planaltina.

Love RM (1949). Estudos citológicos preliminares de trigos rio-grandenses. vol.74. Secretaria da Agricultura do Rio Grande do Sul, Porto Alegre.

Macedo MCM (2009). Integração lavoura e pecuária: o estado da arte e inovações tecnológicas. R. Bras. Zootec. 38: 133-146.

Mackay JHE (1982). Register of Australian herbage plant cultivars. Commonwealth Scientific and Industrial Research Organization, Camberra.

Mendes-Bonato AB, Pagliarini MS, Valle CB and Penteado MIO (2001). Meiotic instability in invader plants of signal grass Brachiaria decumbens Stapf (Gramineae). Acta Scientiarum 23: 619-625.

Mendes-Bonato AB, Junqueira Filho RG, Pagliarini MS, Valle CB, et al. (2002). Unusual cytological patterns of microsporogenesis in Brachiaria decumbens: abnormalities in spindle and defective cytokinesis causing precocious cellularization. Cell Biol. Int. 26: 641-646.

Mendes-Bonato AB, Pagliarini MS and Valle CB (2004). Abnormal pollen mitoses (PMI and PMII) in an interspecific hybrid of Brachiaria ruziziensis and Brachiaria decumbens (Gramineae). J. Genet. 83: 279-283.

Mendes-Bonato AB, Pagliarini MS and Valle CB (2007). Meiotic arrest compromises pollen fertility in an interspecific hybrid between Brachiaria ruziziensis x Brachiaria decumbens (Poaceae: Paniceae). Braz. Arch. Biol. Technol. 50: 831-837.

Moore DS (2007). The basic practice of statistics. (4th edn.). WH Freeman and Company, New York.

Pagliarini MS (2000). Meiotic behavior of economically important plant species: the relationship between fertility and male sterility. Genet. Mol. Biol. 23: 997-1002. 
Pagliarini MS, Valle CB, Santos EM, Mendes DV, et al. (2012a). Microsporogenesis in Brachiaria brizantha (Poaceae) as a selection tool for breeding. Genet. Mol. Res. 11: 1309-1318.

Pagliarini MS, Vieira MLC and Valle CB (2012b). Meiotic behavior in intra- and interspecific sexual and somatic polyploid hybrids of some tropical species. In: Meiosis - Molecular mechanisms and cytogenetic diversity (Swan A, eds.). Croatia, InTech Europe, 472.

Pizarro EA, Valle CB, Keller-Grein G, Schultze-Kraft R, et al. (1996). Regional experience with Brachiaria: Tropical Ameérica - Savannas. In: Brachiaria: biology, agronomy, and improvement (Miles JW, Maas BL e and Valle CB, eds.). CIAT, Cali, 225-246.

Ricci GCL, Pagliarini MS and Valle CB (2010). Genome elimination during microsporogenesis in two pentaploid accessions of Brachiaria decumbens (Poaceae). Genet. Mol. Res. 9: 2364-2371.

Ricci GCL, Souza-Kaneshima AM, Felismino MF, Mendes-Bonato AB, et al. (2011). Chromosome numbers and meiotic analysis in the pre-breeding of Brachiaria decumbens (Poaceae). J. Genet. 90: 289-294.

Risso-Pascotto C, Pagliarini MS and Valle CB (2002). Abnormal nucleolar cycle in microsporogenesis of Brachiaria decumbens (Gramineae). Cytologia. 67: 355-360.

Risso-Pascotto C, Pagliarini MS and Valle CB (2004). Asynchronous meiotic rhythm as the cause of selective chromosome elimination in an interspecific Brachiaria hybrid. Plant Cell Rep. 22: 945-950.

Risso-Pascotto C, Pagliarini MS and Valle CB (2005). Symmetric pollen mitosis I and suppression of pollen mitosis II prevent pollen development in Brachiaria jubata (Gramineae). Braz. J. Biol. Med. Res. 38: 1603-1608.

Shivanna KR (2003). Pollen biology and biotechnology. Sci. Publishers.

Simioni C and Valle CB (2009). Chromosome duplication in Brachiaria (A. Rich.) Stapf allows intraspecific crosses. Crop Breed. Appl. Biotechnol. 9: 328-334.

Simioni $C$ and Valle CB (2011). Meiotic analysis in induced tetraploids of Brachiaria decumbens Stapf. Crop Breed. Appl. Biotechnol. 11: 43-49.

Souza-Kaneshima AM, Simioni C, Felismino MF, Mendes-Bonato AB, et al. (2010). Meiotic behaviour in the first interspecific hybrids between Brachiaria brizantha and Brachiaria decumbens. Plant Breed. 129: 186-191.

Usberti R (1990). Determinação do potencial de armazenamento de lotes de sementes de Brachiaria decumbens pelo teste de envelhecimento acelerado. Pesq. Agrop. Bras. 25: 691-699.

Valle CB and Savidan YH (1996). Genetics, cytogenetics, and reproductive biology of Brachiaria. In: Brachiaria: biology, agronomy, and improvement (Miles JW, Maass BL and Valle CB, eds.). CIAT. 147-163.

Valle CB and Pagliarini MS (2009). Biology, cytogenetics, and breeding of Brachiaria. In: Genetic resources, chromosome engineering, and crop improvement series (Singh RJ, ed.). CRC Press, New York, 103-151.

Valle CB, Simioni C, Resende RMS and Jank L (2008). Melhoramento genético de Brachiaria. In: Melhoramento de forrageiras tropicais (Resende RMS, Valle CB and Jank L, eds.). Embrapa Gado de Corte, Campo Grande, 13-53.

Valle CB, Jank L and Resende RMS (2009). Melhoramento de forrageira tropical no Brasil. Rev. Ceres. 4: 460-472. 